\title{
INVESTIGACIÓN Y MENTIRA
}

\section{Túa Blesa}

Universidad de Zaragoza

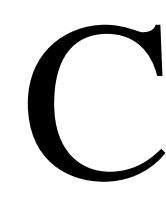

omo el lector ya ha reconocido, el título rehace el de un bien conocido texto de Goethe, Poesía y verdad (Dichtung und Wahrheit). Dejaba advertido allí Goethe que su escrito respondía a un tratamiento del material autobiográfico que tenía de lo poético y de lo histórico, respondiendo esto último, por tanto, habrá que entender, a lo verdadero. Valga lo precedente para dejar advertido que en estas páginas poco hay de poético, aunque sí tiene que ver con la poesía y los estudios literarios, como se verá, y desde luego que todo en ellas tiene que ver con la verdad... y con la mentira. Sí, con la verdad de los hechos, tan terca, y lamentablemente con la mentira de un experto de la Agencia Nacional de Evaluación y Prospectiva (ANEP), un colega de los estudios literarios de la universidad española que, por razones que dejo al lector precisar, es capaz de mentir en un informe oficial amparándose en el sistema de anonimato que rige en el procedimiento de evaluación y calificación de Proyectos de Investigación. Que un proceder como el de este experto supone una burla de la ética es evidente y también lo es que el mendaz incumple todos los compromisos adquiridos con la ANEP -a la que deja, como se verá, en situación de ridículo mayúsculo- y más en general con el sistema de selección de solicitudes de proyectos, que resulta a la vista de los hechos degradado al nivel de las alcantarillas, y en fin con todo lo que un profesor no puede ser de ningún modo, pues está claro que en la docencia y en la investigación la indecencia debería estar desterrada. Immanuel Kant en El conflicto de las facultades reclamaba para la Facultad inferior, la Facultad de Filosofía, una posición que le otorgaba el derecho y el deber de no poder nunca «deponer sus armas ante el peligro que amenaza a la verdad que ella debe proteger» (1963: 42). El funcionario desleal del que aquí se habla ha de pertenecer a esa facultad inferior, donde se integran los estudios filológicos -la condición de filólogo del embustero se deduce de lo que se comenta más adelante-, y, pese a Kant, toma sus armas para escribir datos falsos en documento oficial. Sean cuales sean sus intenciones, las consecuencias de sus falsedades no 
pertenecen ya a la especulación, sino que éstas funcionan como argumentos para otorgar a la solicitud una bajísima calificación. Si se le tomase por síntoma de la universidad española y de los procedimientos de asignación de fondos públicos a la investigación, qué degradación. Si nadie hace nada, qué desolación.

En los sistemas políticos fascistas, me permito recordar, la institución de la censura respondía a ese mismo amor por el secreto que caracteriza al sistema de selección de proyectos. Así, por poner un ejemplo, un censor del franquismo, el "lector 29" - un nombre para el anonimato que encuentra su antecedente en el modo procesal de la Inquisición-, escribía a propósito del original, presentado a censura como era preceptivo, de Actos de Antonio Gamoneda -se trataba de los poemas de lo que años más tarde se publicaría como Blues castellano- en noviembre de 1968 el siguiente informe:

Libro de versos muy malos, de temática y métrica diversa [sic]. Sobre todos ellos campan un sentido de resentimiento y odio [sic]. Muchos de ellos aparecen con citas de Marx, Lefevbre y otros marxistas. La tónica general de la obra es demagógica, pues aunque no lo dice claramente, el ambiente de desolación que pinta se refiere a España. Así mismo, tienen sus toques de ateísmo.

La obra carece en absoluto de valor, pero como hay algunos poemas que pueden ser pasables, se ha preferido señalar en las páginas marcadas, los poemas que deben ser suprimidos. Con estas tachaduras ES PUBLICABLE (apud Palomo García, 2007: 96)

Dejando aparte que en algunas de sus afirmaciones al "lector 29" hay que darle la razón -como en lo relativo al «ambiente de desolación»-, al redactor de esas líneas hay que inscribirlo en la historia inacabable, al parecer, de la infamia y su juicio «Libro de versos muy malos» causa una absoluta vergüenza y una carcajada de las que desencajan las mandíbulas. El experto del que aquí se habla es, como se verá, un digno sucesor de tal lector en la mencionada historia y ¿quedará en la impunidad como su ilustre predecesor?, ¿mentir en un informe oficial es intranscendente?

Como Goethe, entremos en lo histórico, en la verdad. He aquí la relación de los hechos.

Por Resolución del Ministerio de Ciencia e Innovación (BOE 31 de diciembre de 2008) se publicó la convocatoria de Proyectos de Investigación I+D+i. Según se lee allí, «el procedimiento de concesión» sería, como era de esperar en un sistema democrático, «en régimen de publicidad, objetividad y concurrencia competitivas». Perfecto, sobre el papel, perfecto, pero tales criterios ¿se cumplen efectivamente? Como se verá, hay ocasiones en que por causas que habría que averiguar algunas de las personas que intervienen en el proceso introducen tales distorsiones, cometen tales infracciones, que el proceso mismo resulta viciado todo él y la objetividad y la concurrencia competitivas, ésas que quedaban perfecto sobre el papel, se convierten en papel mojado... y por los 
peores de los líquidos. De perfecto a putrefacto. Y esa putrefacción hace que la administración pública, es decir, sus gestores, aquellos que han de velar por cumplir la ley y hacer que se cumpla, actúe de un modo por el cual los ideales de democracia y justicia sean burlados. ¿Ninguna autoridad competente tomará medidas haciéndose entonces cómplice de tal atentado? Hasta ahora, entiendo que por ignorancia -no hay motivos para pensar en otras razones-, han resultado ser cómplices del falsario, ¿continuarán encubriéndolo a partir del momento en que sean conocedores de los graves hechos que aquí se relatan?

Es el caso que junto a profesores de varias universidades presenté como Investigador Principal la solicitud de un Proyecto de Investigación, referencia FFI200913573 (http://cdc.unizar.es/tropelias/doc01.pdf), del que el Subdirector General de Proyectos de Investigación me comunicó la no concesión con fecha 27 de julio de 2009, adjuntando un escrito, "Observaciones de la Comisión de Selección" (http://cdc.unizar.es/tropelias/doc02.pdf), que es todo él una reiterada infracción de las normas de la convocatoria, además de que contiene varias afirmaciones que son, sin más, ridículas o, mejor aún, aberraciones en el campo de los estudios literarios. Ante tal negativa presenté las correspondientes alegaciones (http://cdc.unizar.es/tropelias/ doc03.pdf), en las que se ponían de relieve las aludidas irregularidades y, como no podía ser de otro modo, el Proyecto fue concedido (http://cdc.unizar.es/tropelias/ doc04.pdf). Convendrá dejar dicho ya que causa cierta sorpresa o estupor que, pese a que las mencionadas "Observaciones" conculcan tanto el espíritu como la letra de las normas de la convocatoria, tal y como ponía a la luz el recurso presentado, ninguna de las autoridades implicadas en el proceso ha tomado ninguna medida, pues el hecho es que la llamada Comisión de Selección continuó y hasta el momento continúa estando formada por los mismos miembros que actuaron y fueron puestos en evidencia por las mencionadas alegaciones, por lo que podría pensarse que se premia con la permanencia en tal Comisión el infringir los preceptos que deberían cumplir y velar por que se cumpliesen.

Lamentablemente, he de decir que no me extraña a la vista de cómo va casi todo en la universidad. En el coloquio que siguió a una conferencia impartida el 13 de enero de 2010 en el salón de Actos del Instituto de Ciencias de la Educación de la Universidad de Zaragoza por la Directora de la Agencia Nacional de Calidad y Acreditación (ANECA), la conferenciante, D. ${ }^{a}$ Zulima Fernández, afirmó ante más de un centenar de asistentes que la ANECA, y esto es literal, era una agencia privada. ¿No es asombroso? Sí. Y no sólo asombroso sino contrario a la verdad y al ordenamiento jurídico, pues basta consultar los Estatutos de dicha Agencia para leer en el art. 1.4 que «La Fundación tiene la condición de medio propio y servicio técnico de la Administración General del 
Estado» (http://www.aneca.es/ANECA/Marco-legislativo). En esa misma página se puede leer también que «ANECA es creada el 19 de julio de 2001 por acuerdo de Consejo de Ministros». De ser como la Directora de ANECA dijo, una agencia privada, el Consejo de Ministros tendría unas curiosísimas funciones: ¡crear instituciones privadas! Y además, menudo enredo jurídico el que una institución que «tiene la condición de medio propio y servicio técnico de la Administración General del Estado» sea al mismo tiempo una agencia privada. No es necesario ser un experto en derecho para entender que eso no hay quien lo entienda... porque es imposible. Y en fin, si se consulta la página web del Ministerio de Educación del Gobierno de España (http://www.educacion.gob.es/horizontales/ministerio/organismos.html) se puede leer que uno de los Organismos de dicho Ministerio, y por cierto que el primero que se relaciona, es la Agencia Nacional de Evaluación de la Calidad y Acreditación. Ya que tal Agencia lleva en su nombre la palabra "evaluación", se invita al lector a la evaluación de la mencionada afirmación de su Directora.

A lo anterior se puede añadir, para desgracia de la universidad española, el reciente Borrador del Estatuto del Personal Docente e Investigador, esa gran contribución al desmantelamiento de lo que aún queda por desmantelar y que, por fortuna, está produciendo la respuesta de indignación que como mínimo merece, aunque, tal como están yendo las cosas en los últimos años, no puede descartarse lo peor. Al respecto es de todo interés el Manifiesto contra las barbaridades contenidas en dicho Borrador en http://www.uniseria.blogspot.com/, manifiesto respaldado en el momento de redacción de estas páginas por más de 1.600 firmantes; y aprovecho para decir que Faneca es una alegría y una esperanza.

A todo ello, y el asunto sólo quedará aludido, téngase en cuenta la degradación de lo que la institución universitaria debiera ser que está produciendo el llamado Plan Bolonia. ¿Por qué los responsables de la política educativa no promueven una evaluación del impacto de tal Plan en la enseñanza? Y, dicho sea de paso, ¿por qué la ANECA, la ANEP, agencias que llevan en su propio nombre el término "evaluación", y las que las reproducen en las distintas autonomías, no emprenden un proceso en el que el profesorado de la universidad española evalúe sus actuaciones?, ¿es que alguien en tales agencias teme esa evaluación?

Pero volvamos al relato de los hechos que motivan estas páginas, a la verdad... de la mentira. Dado que en mi opinión la solicitud era sólida y estaba además avalada por los resultados a los que había dado lugar un Proyecto anterior, el HUM2006-04981, desarrollado por un equipo investigador en el que habían participado prácticamente los mismos integrantes del equipo del FFI2009-13573 y del que yo mismo era IP, solicité con fecha de 28 de septiembre de 2009 (http://cdc.unizar.es/tropelias/doc05.pdf) se me 
facilitase copia de todos los informes y documentos a los que la solicitud hubiese dado lugar y junto a un escrito de de remisión del Jefe de Departamento de Humanidades y Ciencias Sociales del MICINN, de 7 de enero de 2010, recibí cinco informes de otros tantos expertos (http://cdc.unizar.es/tropelias/doc06.pdf). Informes que, pese al criterio de transparencia, me fueron enviados como anónimos. ¿Transparencia opaca?

En el mencionado escrito de remisión se dice: «Le incluyo dos informes de Expertos del MICINN, uno del Responsable de Área de la ANEP y dos de expertos de la $\mathrm{ANEP}$ », con lo que al menos de uno de tales informes se apuntaba la autoría. La adjunta del área de Teoría de la literatura y literatura comparada en dicha Comisión, es decir, «el Responsable de Área», era y es, según la página web de la ANEP, la profesora Sultana Wahnón Bensusan, catedrática de la Universidad de Granada. Su informe es, como el lector puede comprobar aun sin ser un experto hermeneuta, el texto que sirvió de base para la redacción de las "Observaciones de la Comisión de Selección” y, por tanto, una sucesión de infracciones a las normas de la convocatoria y algunas afirmaciones sobre asuntos literarios francamente impropias de un profesor universitario. A las alegaciones contenidas en el Recurso mencionado (http://cdc.unizar.es/tropelias/doc03.pdf) me remito. Sin embargo, no creo improcedente retomar aquí algo del informe de «el Responsable de Área» con algún comentario.

Refiriéndose a lo que se decía de los resultados del Proyecto de 2006 en la Solicitud, se lee que «los resultados del proyecto han consistido hasta ahora solo en resultados parciales, en concreto veintinueve artículos independientes sobre autores particulares, de los cuales además solo dieciseis [sic] son aportaciones sobre pensadores (Ortega...), filólogos (Blecua...) o creadores-teóricos (Guillermo de Torre). El resto versa sobre poetas y creadores, que, como Valverde, cuentan con una producción teórica muy escasa».

Tales afirmaciones exigen, al menos, estos comentarios:

1. No es cierto que sean veintinueve (29) los trabajos realizados en el marco del Proyecto de 2006, sino cuarenta y siete (47). De ellos, veintiuno (21) publicados en los volúmenes Pensamiento literario español del siglo XX, 1 y Pensamiento literario español del siglo XX, 2 (Blesa et al., eds., 2007 y 2008), estando en aquel momento pendientes de publicación los restantes.

2. La distinción entre «pensadores», «filólogos» y «creadores-teóricos» parece excluir el pensamiento de todos aquellos escritores que no se sitúen en el campo de la filosofía o de la teoría literaria académica. No era eso lo que los Proyectos de 2006 y 2009 proponían: tanto uno como el otro tienen 
en el título la expresión «Pensamiento literario» y es que hasta un alumno de primer curso de cualquiera de las licenciaturas, incluso los de los actuales grados, de materias filológicas sabe bien que pensamiento literario hay en cualquier tipo de texto, sea éste de creación, crítico, historiográfico, etc. Forma parte del saber mínimo en los estudios literarios que no hay texto que no responda a unos presupuestos teóricos, es decir, a un pensamiento.

3. Afirmar que una parte de los trabajos realizados en el ámbito del Proyecto de 2006 versa «sobre poetas y creadores, que, como Valverde, cuentan con una producción teórica muy escasa» debería sonrojar a cualquiera. Además de por lo apuntado en el párrafo anterior, es decir, teoría hay en cualquier clase de texto, ¿de verdad piensa «el Responsable de Área» que José María Valverde cuenta con una producción teórica muy escasa? Remito al lector al libro de Juan Carlos Pueo, por cierto, miembro del equipo de los dos Proyectos, El pensamiento literario de José María Valverde (Pueo, 2011), donde podrá comprobar, si es que le es necesario, lo ridículo de tal afirmación. Además ¿cree «el Responsable de Área» que cuentan con una producción teórica muy escasa autores como Antonio Machado, Luis Cernuda, José Ángel Valente o Pere Gimferrer, por citar a algunos de los estudiados por los miembros del equipo? Si es así, apaga y vámonos.

De manera muy breve, dejaré señalado que sorprende la enorme discrepancia en la valoración de la Solicitud. Comentarios aparte, la calificación que ésta mereció en los informes, según el orden en que me fueron remitidos, es la siguiente: 37-31-31-9-46. Es sobresaliente, y se desvía con rotundidad de las restantes, la bajísima calificación que en el informe 4, el de uno de los dos «expertos de la ANEP», se concedió al Proyecto solicitado, lo que por sí mismo ya es llamativo, pero podría entenderse como un juicio particular, legítimo, si no fuera porque la lectura del informe muestra el ilícito que contiene y que lo hace inválido: la falsedad en documento oficial por alguien que es funcionario o, en su defecto, está cumpliendo con una función pública. Mentir en un documento, qué gracia.

Vayamos, pues, a él. Que el denominado «experto de la ANEP» autor de tal informe vierta juicios negativos sobre mi trabajo es algo que en principio entra dentro del libre ejercicio de la crítica, bien es verdad que si el denominado experto piensa tales cosas de mi actividad investigadora lo deseable hubiera sido que lo hubiera dicho públicamente, en sus propias publicaciones, pues así son las cosas en el mundo de la investigación. Pero no, por la razón que sea, ha callado y cuando habla, y miente, es en 
un informe oficial, claro que amparado en el secreto que el anonimato del procedimiento le facilita. Ese informe, como ya se ha dicho, retrata a un docente, un funcionario, para el que la ética no pasa de ser un sustantivo esdrújulo y, en consecuencia, pone en entredicho todo el procedimiento y deja a la ANEP, con la que se comprometió a ser objetivo, imparcial, es decir, honesto, es decir, un funcionario, en el mayor de los ridículos. Por cierto, la adjunta del área de Teoría de la Literatura y Literatura Comparada, miembro de la Comisión y colega de mi misma área, ¿no vio que en el informe del "experto" se vertían falsedades?, ¿es la responsable y no respondió? Si lo vio, debería, como mínimo, haberlo desechado. Y si no lo vio, ello habla de la desidia de su proceder.

Todavía más. En su informe el "experto" -aunque es obvio, quede dicho que el uso de comillas es aquí marca de ironía, pues en lo único que el profesor de la universidad española que redactó ese informe es experto es en mentir y redactar al dictado de la miseria moral- llega a decir entre otras cosas:

Los 'teóricos de la literatura' españoles o son filólogos, o son descriptivistas, pero no son de forma efectiva teóricos de la literatura. ¿Cuáles son sus teorías? ¿Qué teorías literarias se han generado en España durante los últimos 18 años, por ejemplo?

Sin entrar a responder a tal cuestión en este momento, aunque tiempo habrá, resulta para empezar enigmático qué acontecimiento, qué desastre, ocurrió en 1991 que hizo que la producción del conjunto de los profesores de la mencionada área sea desde esa fecha fatídica, ya que no inexistente, pues trabajos hay, inane. Queridos colegas del área, sabedlo, para este "experto" nuestras publicaciones, las de todos nosotros, están, al menos las del período 1991-2009, en las antípodas de la teoría: ¡filólogos, más que filólogos!, ¡descriptivistas, más que descriptivistas!, eso es lo que somos.

Podría recordarse aquí cómo hace ya años Paul de Man diagnosticó que en los estudios literarios se daba una resistencia a la teoría, con lo que podría pensarse que, entre otros motivos, el "experto" sufre de ese mal, pero más bien parece que no es oportuno recordarlo, pues siendo que las publicaciones de los investigadores adscritos al área de Teoría de la Literatura y Literatura Comparada son teoría sin teoría sería ocioso.

De lo anterior se deduce, por otra parte, que el "experto" no debe de pertenecer, o no debe, al área de Teoría de la Literatura y Literatura Comparada, pues de estar adscrito a ella estaría descalificándose a sí mismo y no resulta probable que sea así. Además, dado que el Proyecto que se solicitaba tenía, y tiene, por título "Pensamiento literario español del siglo XX y su contextualización", es decir, se centra en la literatura española, hay alguna razón para pensar que el redactor de falsedades ha de ser un profesor del área de Literatura Española. Y no es uno cualquiera. En absoluto. Según se 
desprende de sus palabras se ha leído todos y cada uno de los trabajos que cientos de profesores del área de Teoría hemos publicado durante años, como mínimo los del período 1991-2009, aunque ha de suponerse que tiene leídos también algunos de los que se publicaron antes de la hecatombe de la Teoría en España, de ahí que pueda fechar el año en que dio comienzo la pertinaz sequía. Qué ejemplo de dedicación. Claro que a la luz de lo que se dice más adelante el modo de leer textos del "experto" es de lo más curioso.

Pero no puede pasarse por alto, que, si en el informe del "experto" se afirma que todas las publicaciones del profesorado de Teoría son de teoría-no-teoría, habrán de estar necesariamente incluidas las investigaciones de la propia profesora Wahnón. ¿Leyó eso la «Responsable de Área» y se quedó impasible?, ¿piensa ella como el "experto"?, ¿lo piensa de todos los colegas del área?, ¿piensa eso de su propia producción científica? Sería bueno que diera alguna respuesta. De momento, y a expensas de lo que tenga a bien responder, presumiblemente lo piensa, pues el hecho -lo histórico, lo verdadero- es que dio por bueno el informe y lo adjuntó a la documentación.

Pero vayamos a lo que es lo decisivo: las mentiras del "experto". Se dejaba constancia en la solicitud del Proyecto en cuestión de que en el marco del Proyecto anterior, el HUM2006-04981, se habían elaborado una serie de trabajos, presentados todos ellos en seminarios, de los cuales en ese momento estaban publicados $23 \mathrm{y}$ el resto pendientes de publicación ${ }^{1}$. Pues bien, el experto en mentiras -ahora sin comillas, es decir, en sentido recto- escribe a propósito de tales trabajos:

\begin{abstract}
Muchos de estos artículos son artículos de prensa. (Confieso que algo así me parece escandaloso) [y a continuación reincide en eso mismo con alguna precisión más] Muchos de estos artículos, buena parte de ellos publicados en la prensa, son de una vulgaridad y de una trivialidad sobresalientes: «Carlos Bousoño: la poesía y el chiste», «Barthes, la tele, la parodia: Salvador Gutiérrez Solís y la narrativa mutante», etc.
\end{abstract}

A tales afirmaciones, que no se olvide constan en documento oficial, hay que responder:

1. Ni uno solo de los trabajos del Proyecto HUM2006-04981 está publicado en la prensa. Pero ¿en qué cabeza cabe eso?, ¿cómo se van a publicar en la prensa trabajos de veinte o más páginas de naturaleza académica? La lógica más elemental dice que tal cosa es imposible o ¿hay algún periódico en el

\footnotetext{
${ }^{1}$ Pueden leerse en Blesa et al., eds, 2007 y 2008. Con posterioridad, y hasta la fecha, otros trabajos elaborados en el marco de uno y otro Proyecto se han publicado en Blesa et al., eds, 2009, 2010 y 2011 y alguno más en otros lugares.
} 
mundo que publique esa clase de trabajos? Y aun en el caso de que los hubiere, es rotundamente falsa la afirmación del "experto" y lo es en las dos ocasiones en que la escribe, hecho este de la repetición que excluye la posibilidad de error o de errata, salvo que repetir dos o más veces una mentira haga que se transforme en verdad.

Si al "experto", llamémosle ahora ya farsante, le parecía escandaloso que los trabajos producidos dentro del marco de Proyecto de Investigación fueran publicados en la prensa, lo escandaloso es para mí decir falsedades en un informe y lo es la dejadez de la Comisión de Selección que dio por buena tan burda mentira (¿para qué se exige adjuntar los CV's de los miembros de los equipos?); y puedo aventurar que tal proceder será juzgado como escandaloso, por lo menos escandaloso, por la comunidad científica.

2. ¿Grave lo anterior? Sí, sin duda, pero resulta casi una nimiedad cuando se compara con esto otro. El experto mendaz juzga severamente, como ya se ha visto, «muchos» de los trabajos producidos en el marco del Proyecto. De ellos cita expresamente dos y un «etc.» hace saber que son varios más los que al leerlos le han parecido «de una vulgaridad y de una trivialidad sobresalientes». Podría ser una opinión, que desde luego yo no comparto de ningún modo, pero ¡qué mala fortuna la del experto en falsedades! O tiene dotes de clarividencia, es decir, es una reencarnación de Rappel -no merece desde luego ser comparado con la Pitia-, o, lo que es más cierto, no encuentra límites en su miento-como-escribo y, creyéndose a cubierto por un sistema que se funda en el anonimato, esa figura de raigambre fascista, se permite emitir juicios sobre trabajos que en el momento de redactar su informe estaban inéditos. Asombroso, en efecto. Ese "experto" es capaz de juzgar trabajos que no ha podido leer de ninguna de las maneras, ni en esa prensa a la que alude ni en ningún otro lugar. Por cierto, ¿es con ese mismo método de lectura con el que ha leído la producción completa del período 1991-2009 de cientos de investigadores del área de Teoría, esos ya filólogos, ya descriptivistas?

Y nadie de la Comisión advirtió, ni siquiera el Responsable de Área, esta nueva falsedad. Nuevo asombro.

Lo que es verdad es esto: «Carlos Bousoño: la poesía y el chiste», que el "experto" juzga y, por tanto, da por leído, estaba inédito en el momento del informe y de ningún modo es ni vulgar ni trivial sino todo lo contrario y al mismo me remito 
(véase en Blesa et al., eds., 2010: 123-134). Como el lector habrá observado, la fecha de publicación es 2010. Y se puede precisar algo más: los primeros volúmenes salieron de la imprenta el día el 28 de octubre de 2010, fecha en que dio comienzo el VII Seminario «Pensamiento literario español del siglo XX», celebrado en la Universidad de Zaragoza. Pues bien, si el mencionado trabajo no pudo leerse hasta el día 28 de octubre de 2010 y es de 27 de julio de 2009 -anterior en más de un año- la fecha del escrito en que se me comunicó que el Proyecto no había merecido la aprobación, y sobra decir que el informe ha de ser anterior a tal fecha en al menos algunos meses, ¿dónde lo leyó el "experto"?, ¿en esa prensa especializadísima que él frecuenta?: ya sabemos que no, porque no hay tal; ¿en el libro en el que está publicado?: ya sabemos que es imposible, porque se publicó más de un año después. En consecuencia, agotadas las vías especulativas, la única respuesta es que sus afirmaciones son falsas. Ésa es la verdad, su falsedad.

Sobre la publicación de los trabajos en la prensa -es decir, en la no publicaciónañade el "experto" un juicio moral: «Confieso que algo así me parece escandaloso». Y a mí también me lo parecería, pero el caso es que su confesión no se evapora, sino que regresa para recaer ahora sobre su propio proceder. Ahora sin comillas y referido al informe del mentiroso: confieso que algo así me parece escandaloso. Eso sí que es escandaloso, "experto" en mentiras, eso sí.

Por su parte, «Barthes, la tele, la parodia: Salvador Gutiérrez Solís y la narrativa mutante» estaba inédito en el momento de redacción del informe y ese mismo es su estado en estos momentos. Cuando se publique, se podrá opinar, pero ¿antes? De manera que, de nuevo sin comillas: confieso que algo así me parece escandaloso. Eso sí que es escandaloso, experto de la ANEP, "experto" en mentiras, eso sí.

¿Cómo pudo juzgar el "experto” lo no publicado?, ¿dónde vio esas vulgaridades y trivialidades de las que habla? Misterio. De todos modos, se me ocurre a modo de hipótesis que el "experto" leyó esos títulos en la solicitud del Proyecto y debieron de parecerle extravagantes; chistes, la tele, mutante, «Bah, se dijo, vulgaridades y trivialidades» y lo escribió. Si así fue, delataría que no sabe nada, pero nada de nada del libro de Carlos Bousoño que se alude en el título de uno de los trabajos y que no es otro que Teoría de la expresión poética (Madrid, Gredos, 1952; 5a ed. 1970, muy aumentada), donde este estudioso de la literatura basa su concepción de lo poético a partir de la distinción, dentro de lo que se podría denominar «lenguaje literario», entre la poesía y el chiste. Y poco debe de saber de la obra de Roland Barthes, de la de Salvador Gutiérrez Solís y de lo que se viene denominando narrativa mutante. Si es así, hala, "experto", a leer y a estudiar, que ha quedado fidedignamente demostrado que no eres ni filólogo ni descriptivista, ni ninguna otra cosa salvo experto en mentiras. 
Citando una vez más al "experto”, ese nuevo "lector 29”, confieso que algo así me parece escandaloso.

Sí, escándalo. Un escándalo que alcanza al "experto" -confieso que darle ese nombre hace que me dé la risa, pero «Risum teneatis», que escribió Horacio-, a la Responsable de Área, profesora Sultana Wahnón Bensusan -¿en qué grupo de noteóricos entrará ella?, ¿será filóloga?, ¿será descriptivista?-, al conjunto de la Comisión, a la Agencia Nacional de Evaluación y Prospectiva y al resto de organismos que participan en el proceso de selección de Proyectos. Un escándalo que pisotea los valores de justicia y de democracia, envilecidas ambas por el falso experto, tanto cuanto funcionario desleal.

Sr. Subdirector General de Proyectos de Investigación del MICINN -a quien remito copia del contenido de estas páginas-, lamento comunicarle que su resolución por la que se comunicaba que mi Solicitud había obtenido una calificación $\mathrm{C}$ estaba fundamentada, en parte, en falsedades. ¿Permanecerá Vd. impasible? Más en general, ¿provocará el conocimiento de todo este gravísimo proceder del "experto" alguna actuación por parte de las autoridades competentes?, ¿dará igual esta forma de corrupción que contamina todo el procedimiento? El mal olor que expele ese informe llega hasta Dinamarca.

Aunque como he escrito, no voy a responder aquí a las afirmaciones del "experto" sobre mi trabajo, sí creo necesarias algunas observaciones. Según se lee en el reiterado informe, los libros que yo tenía publicados en el momento de la solicitud, le parecían «muy pocos, y muy poco relevantes». Es un juicio. $\mathrm{Y}$ añade que «se trata de libros referidos esencialmente a poesía y de modo muy concreto a Leopoldo Panero». De ser cierto, que no lo es, pues basta comprobar que en mi currículum que acompañaba a la solicitud hay trabajos sobre otros autores y otros temas, no alcanzo a ver en qué se fundamentaría el reproche, dejando aparte, por supuesto, la confusión de Leopoldo Panero con Leopoldo María Panero, que es irrelevante (aunque, en mi opinión, no es irrelevante la categoría literaria de la obra de uno y otro escritor, pero ésta es otra cuestión).

De mayor interés es esto otro: «El resto de los artículos, reseñas y contribuciones a congresos que presenta el IP versan básicamente sobre los mismos temas: poesía y deconstrucción». Tampoco veo el fundamento de su reproche, es más, aunque fuese cierto, creo que «poesía y deconstrucción» podría ser el lema de toda una vida de investigador.

En otro de los pasajes de su putrefacto informe se muestra el "experto" muy preocupado por el destino y buen uso de los fondos públicos, pues escribe que: 
Es en realidad sorprendente que a este equipo [el del Proyecto HUM2006-04981, casi idéntico al de la Solicitud] le haya sido concedido un proyecto de investigación con anterioridad. No se comprende, en términos científicos, semejante concesión. Y, a juzgar por los resultados, sus aportaciones son tales que debería exigírseles la devolución de los fondos entregados en su momento.

A lo que hay que añadir esto otro que se lee más adelante en el mismo informe:

Es un error subvencionar algo de esta naturaleza [el Proyecto FFI2009-13573 que se solicitaba]. Y sorprende mucho que haya podido ser subvencionado durante los últimos tres años [HUM2006-04981].

Este lector de capacidad descomunal que se ha leído, según ya sabemos, miles de trabajos de los investigadores en teoría de la literatura para encontrar tan sólo el vacío que contienen -perdón, lo que hay en ellos de filología y descripción-, ese que ha "leído" hasta trabajos inéditos y los valora con todo desparpajo se erige en estos párrafos que he citado en garante de la buena gestión de los fondos públicos y en juez de la Comisión de Selección y de los expertos que calificaron positivamente el Proyecto HUM2006-04981 y de quienes posteriormente dieron el visto bueno a cada una de las sucesivas memorias anuales que fui presentando incluida la final, que mereció la calificación de «Muy Satisfactorio» ${ }^{2}$, y desde ese encumbrado lugar descalifica a todos. Y por dos veces, rasgo de composición este de la repetición que al parecer va ligado a la mentira. Sabedlo, pues, miembros de la Comisión y expertos, para este "experto" habéis dado vuestro visto bueno a un despilfarro de los fondos públicos y eso fue un «error», mendax dixit. Ya oigo vuestros golpes en el pecho.

Ahora bien, ¿quién no estará de acuerdo en que los fondos públicos han de ser bien gestionados? En efecto, en el fondo del asunto no se puede estar sino en la misma posición que ha hecho suya el "experto". Sin embargo, algo tremendo regresa: el "experto" ha escrito falsedades en un documento oficial y iha cobrado por mentir! Así, lo que «es en realidad sorprendente», lo que es «escandaloso», para usar sus propios términos, es que este individuo corrupto por obra y gracia de sus mentiras acaba siendo el ejemplo del peor uso imaginable de los fondos públicos, el del funcionario falsario, el que pone a la ANEP y a todo el proceso de selección de proyectos en el lugar de la abyección. ¿No debería exigírsele al mentiroso que devuelva la cantidad que cobró por esparcir sus mentiras en un informe oficial? Es más, ¿será ésta la única ocasión en que lo ha hecho?, ¿no se deberían investigar todos los informes que pudiera haber realizado

\footnotetext{
2 «En contestación al informe de seguimiento del proyecto de referencia HUM2006-04981 y de título "PENSAMIENTO LITERARIO ESPAÑOL DEL SIGLO XX", del que es usted investigador principal, le informo de que ha sido valorado con la calificación: Muy Satisfactorio», así en escrito de la Subdirección General de Proyectos de Investigación de fecha 5 de septiembre de 2011.
} 
para la ANEP, la ANECA, el MICINN y cualquier otra institución pública? ¿Nadie actuará?

Bastantes otras lindezas del "experto" están reclamando un comentario -ese estilo desabrido y falto de toda gracia, por ejemplo-, pero lo ya dicho, creo, muestra a las claras la catadura moral de quien sea el autor. Sus falsedades en documento oficial están aquí al descubierto. ¿Nadie le pedirá cuentas? Yo, en mi nombre y, con toda modestia, en el de toda la comunidad científica, solicito a las autoridades competentes den a conocer la identidad de quien resulte ser el autor del informe de los embustes y den noticia de todas las actuaciones que emprendan una vez que sean conocedores de los hechos $^{3}$. Si la ANEP quiere preservar el anonimato de sus expertos, ¿lo hará también en un caso como éste en que el "experto" ha viciado el procedimiento incumpliendo su propio compromiso de objetividad, verdad, etc.?

Consultados varios juristas, me hicieron ver que estos hechos están recogidos en el Código Penal. Así es, en su capítulo II, «De las falsedades documentales» se lee en el art. 390 que

1. Será castigado con las penas de prisión de tres a seis años, multa de seis a veinticuatro meses e inhabilitación especial por tiempo de dos a seis años, la autoridad o funcionario público que, en el ejercicio de sus funciones, cometa falsedad: esencial.

1. Alterando un documento en alguno de sus elementos o requisitos de carácter

2. Simulando un documento en todo o en parte, de manera que induzca a error sobre su autenticidad.

3. Suponiendo en un acto la intervención de personas que no la han tenido, o atribuyendo a las que han intervenido en él declaraciones o manifestaciones diferentes de las que hubieran hecho.

4. Faltando a la verdad en la narración de los hechos.

En consecuencia y dado que la conducta del "experto" se ajusta estrictamente a lo ahí establecido, ese faltar a la verdad, interpuse una querella (http://cdc.unizar.es/tropelias/ doc07.pdf), que la jueza del Juzgado de Instrucción n ${ }^{\circ} 10$ de Zaragoza, Da María José Bello Thomann desestimó en un auto (http://cdc.unizar.es/tropelias/doc08.pdf), en el que entre otras cosas se lee que «no estamos ante datos objetivos sino ante juicios de valor», lo cual dista tanto como sea posible de la verdad objetiva e indiscutible. Con el respeto que el auto y la persona que lo dicta me merecen, afirmo que no es un juicio de valor sino un dato objetivo que es falsa la afirmación del "experto" de que muchos de los trabajos están publicados en la prensa y que no es un juicio de valor sino un dato objetivo que los trabajos que el "experto" juzga vulgares y triviales de manera

\footnotetext{
${ }^{3}$ Como este "Investigación y mentira" está concebido como un trabajo en marcha, iré dando a conocer en sucesivas entregas en este mismo lugar todo lo relacionado con los hechos que se relatan de los que sea sabedor con la reproducción de los documentos pertinentes.
} 
sobresaliente estaban inéditos cuando emitió tal valoración. La realidad es que se trata, lisa y llanamente, de hechos que son falsedades.

Contra dicho auto se presentó el oportuno recurso (http://cdc.unizar.es/tropelias/ doc09.pdf), que fue nuevamente desestimado por la Sección 3 de la Audiencia Provincial de Zaragoza en Resolución de los magistrados D. José Ruiz Ramo, Presidente, y D. Miguel Ángel López y López de Hierro y D. Mauricio Murillo GarcíaAtance, eso sí, con una argumentación que nada tiene que ver con la del auto anterior (http://cdc.unizar.es/tropelias/doc10.pdf), lo que no deja de ser curioso. Pese a lo que en esa Resolución se dice, la realidad es que el informe del "experto" de la ANEP falta a la verdad y es, por tanto, un caso que ilustra a la perfección lo que dispone el citado artículo del Código Penal. Prescindiendo de otras observaciones que deberían figurar aquí, no creo improcedente llamar la atención sobre lo que se lee en la Resolución mencionada a propósito de las expresiones «en prensa» y «en la prensa». Sin comentarios.

Pese a la inadmisión, dice la Resolución, refiriéndose a las afirmaciones del "experto" de la publicación en la prensa de muchos de los trabajos tantas veces mencionados, que es cierto que «parecen no responder a la realidad» y un poco más adelante escriben los citados magistrados que «Nos encontraríamos, en su caso, ante una infracción administrativa que el querellante puede debatir en dicha sede».

Sea. Se remiten a la Dirección de la Agencia Nacional de Evaluación y Prospectiva, como órgano para el que el "experto" redactó su informe, y a la Secretaría de Estado de Universidades, y a la Secretaría de Estado de Investigación, en cuanto que son los organismos de los que emanó la Resolución de la convocatoria de ayudas para la realización de proyectos de investigación, norma a partir de la cual se han venido sucediendo los hechos narrados, escritos que dan cuenta de los mismos. Las respuestas que reciba de cada uno de estos organismos así como las actuaciones de cada uno de ellos pasarán a formar parte de las páginas de una nueva entrega de «Investigación y mentira», a la cual quedan invitados a colaborar cuantos investigadores y lectores en general lo deseen, páginas, las actuales y las futuras, cuyo origen es la mentira y que buscan que prevalezca la verdad.

\section{Referencias bibliográficas}

Blesa, T. et al., eds. (2007): Pensamiento literario español del siglo XX, 1. Zaragoza, Trópica-Anexos de Tropelías.

- (2008): Pensamiento literario español del siglo XX, 2. Zaragoza, Trópica-Anexos de Tropelías. 
480 | Tropelías. Revista de Teoría de la Literatura y Literatura Comparada, 18 (2012)

Túa Blesa

- (2009): Pensamiento literario español del siglo XX, 3. Zaragoza, Trópica-Anexos de Tropelías.

— (2010): Pensamiento literario español del siglo XX, 4. Zaragoza, Trópica-Anexos de Tropelías.

- (2011): Pensamiento literario español del siglo XX, 5. Zaragoza, Trópica-Anexos de Tropelías.

Kant, I. (1962): El conflicto de las facultades. Trad. Elsa Tabernig. Buenos Aires, Losada.

Palomo García, C. (2007): Antonio Gamoneda. Límites. León, Universidad de León.

Pueo, J. C. (2011): El pensamiento literario de José María Valverde. Vigo, Academia del Hispanismo. 